\title{
Leitura Interpretativa sobre Relações Céu-Terra entre os Indios Tikuna
}

Priscila Faulhaber ${ }^{\mathrm{a}}$

O presente trabalho focaliza o impacto da cosmovisão Tikuna no exame da iconografia de rodas rituais. Analisa tal reverberação, considerando ações simbólicas referentes ao entendimento do pensamento Tikuna no que se refere às relações céu terra, bem como os efeitos das alterações da meteorologia e do ambiente sobre as estratégias de subsistência. Está no centro da analise a significação das figuras pintadas sobre o objeto Mawü ou dono da chuva, bem como da dança executada pela artesã tomou o artefato em seus braços enquanto explicava os seus significados. Tais reflexões são estabelecidas no quadro da apreensão etnográfica do ritual de puberdade feminina Tikuna, abrangendo antropologia e astronomia cultural.

Cosmovisão Indígena; Índios Tikuna; Relações Céu-Terra; Ritual de Puberdade; Astronomia Cultural.

Consideram-se no presente trabalho aspectos do conhecimento Tikuna ${ }^{2}$. Focaliza-se seu conhecimento sobre as relações céu-terra que abrangem a relação do movimento celeste com os fenômenos meteorológicos e suas implicações para as práticas de subsistência. Este estudo está articulado ao projeto de pesquisa sobre os artefatos Tikuna no Museu Goeldi de Belém e no Museu Nacional do Rio de Janeiro, no qual é estabelecido diálogo com a antropologia dos Tikuna, tomando

a Pesquisadora Titular da Coordenação de História da Ciência do Museu de Astronomia e Ciências Afins. Email: pfaulhaber2016@gmail.com. 
como marco inicial a monografia de Curt Nimuendajú (1952). Levei a Puerto Nariño (Colômbia) fotos desses artefatos para mostrá-las aos Tikuna do Resguardo Ticoya e registrar seus comentários sobre eles. Fiz isso tendo em mente a avaliação do sistema de significados em jogo. Em tal procedimento, tratava-se de dar continuidade à análise da iconografia dos artefatos Tikuna, buscando interpretar aspectos intangíveis dos objetos rituais.

Está no centro da análise do presente trabalho a roda celeste Mawü que a especialista Tikuna Wẽtanüna Tchoatüna - do clã Tcheweru ou Awai pequeno (Thevetia sp), conhecida por Alba Lucia Cuellar - presenteou ao projeto $^{3}$ no fim da estiagem. Finalizando a descrição do artefato, ela começou a cantar e dançar, antecipando a chuva que iria chegar em breve. Segundo a artesã, Mawü significa na língua Tikuna 'dono da chuva'. Considera-se em tais artefatos o impacto de práticas rituais Tikuna.

Tal reverberação cultural é constituída em estruturas socialmente diferenciadas, ainda que conectadas em situações de contato interétnico há mais de 300 anos. Reputa-se aqui aos conhecimentos indígenas o status de formas de entendimento tão relevantes quanto os meios manejados pela ciência moderna, e a eles complementares.

No decorrer de seu depoimento, quando explicava o significado da iconografia, a artesã Wẽtanüna Tchoatüna tomou a roda celeste em seus braços e começou a cantar e dançar a cantiga de Mawü, o dono da chuva. Registrei sua ritualização por meio de vídeo, sendo a única expectadora presencial ${ }^{4}$. A função da roda celeste confeccionada pela artesã no ritual de puberdade feminina foi redimensionada na interação com a presente pesquisa. Ao doar o artefato por ela produzido, empregou recursos rituais, cantando e dançando com a roda entre os braços durante seu depoimento. Nesse caso, a artesã dirigia-se não apenas à sua interlocutora presencial, mas a uma audiência virtual, ou seja, a todos que poderiam vir a assistir o vídeo, seja em apresentações da pesquisa, seja no caso de utilizar a peça e as gravações em um projeto expográfico. 
Cabe examinar como os Tikuna com quem interagi trataram, ao contemplar tais artefatos, dos efeitos dos movimentos celestes e meteorológicos em suas práticas sociais. Entende-se que seus conhecimentos são concebidos de acordo com as correlações entre o que ocorre no céu e processos atmosféricos relacionados aos assuntos humanos. Os Tikuna adéquam suas estratégias a processos da esfera pública, nos quais fatores culturais, ambientais e sociais são indissociáveis.

\section{Artefatos e fronteiras em pesquisas sobre o povo Tikuna}

Já foi observado que as generalizações sobre 'conhecimentos tradicionais' ou 'conhecimentos indígenas' devem estar articuladas a cuidadosas etnografias sobre o 'conhecimento situado' de povos indígenas específicos (Nazarea 2005), considerando cada 'situação etnográfica' em sua particularidade (Oliveira 2015). Se lida no presente trabalho com a crítica cultural em termos da escrita etnográfica multissituada (Marcus1998) e cujo entendimento depende da reflexividade antropológica. Baseando-se na tradução cultural, esta deve evidenciar aquilo que não pode ser traduzido, uma vez que os próprios encontros etnográficos são perpassados por discursos e práticas produzidos em situações de dominação.

Considera-se, na trilha da antropologia do conhecimento de Fredrik Barth (2002), a teoria antropológica como um meio de articular diferentes formas de conhecimento. Partimos aqui do caráter performativo dos rituais, narrativas e desenhos Tikuna que podem ser focalizados no âmbito assertivo sobre a cosmovisão, bem como em seus aspectos prescritivos sobre a maneira de seguir os ensinamentos dos heróis culturais Tikuna.

O presente trabalho parte de um conhecimento prévio baseado no entendimento etnográfico dos índios Tikuna, que vivem milenarmente no alto Solimões e ocupam atualmente um território na fronteira entre Brasil, Colômbia e Peru ${ }^{5}$. A situação conflituosa que vivenciam tem raízes em processos coloniais, ainda que disputas interétnicas remontem a conflitos entre povos vizinhos mesmo antes 
da colonização. Nos dias atuais, reconhecem a si mesmos a partir das diferenças étnicas, percebendo as diferentes identidades nacionais.

Os Tikuna do Brasil, da Colômbia e do Peru vivem hoje problemas que perpassam as diferentes situações nacionais, independentemente do país onde estejam localizados geograficamente. $\mathrm{O}$ preconceito difundido pela rede de atores regionais a respeito dos índios leva a uma atitude generalizada de desrespeito em relação à sua integridade física e cultural. Esse preconceito apresenta o inverso da concepção idílica e romantizada da identidade e da cultura indígena, igualmente equivocada por desconhecer os índios de carne e osso e por não fazer referência direta a eles, desqualificando-os por não corresponderem à imagem construída do ponto de vista da sociedade que se autoconsidera civilizadora.

A leitura da bibliografia sobre os Tikuna produzida no Brasil, na Colômbia e no Peru mostra que se trata de um único povo, ainda que se verifiquem diferenças de país para país, dada a sua heterogeneidade, que produz variações de aldeia para aldeia e mesmo de grupo vicinal para grupo vicinal. Essa heterogeneidade e essas variações são comprováveis por pesquisas de campo nos diferentes países. Os relatos históricos e os relatos míticos coletados nessas pesquisas são passíveis de comparação antropológica.

A despeito do processo em curso de urbanização, observa-se um movimento no sentido de fixar residência em colinas não inundáveis - que constituem lugares de significação étnica, em uma aproximação com os valores do povo Magüta, como Enepü, Otaware - ou ao longo do igarapé São Jerônimo (Tonetü), entre as quais se destaca Barro Vermelho ou Bunecü, comunidade na qual tem-se travado relações no decorrer deste projeto, destacando-se estadias em setembro de 1997, maio de 2002 e fevereiro de 2010. As colinas mais altas são consideradas locais inatingíveis pelos mortais, ainda que acessíveis em viagens mentais pelos pajés, pelos anciãos especializados nos conhecimentos dos encantados, pelas meninas-moças durante o ritual de puberdade. Entre tais elevações de terras ou 'montanhas' encantadas, destaca-se o 
Eware, localizado próximo a esse lugar onde vivem os 'imortais'. Verifica-se, no entanto, a continuidade de um movimento, já tradicional, de busca das facilidades da beira rio, o que implica um distanciamento dos valores do povo Magüta e uma aproximação do mundo dos brancos. Existe uma grande diversidade sociocultural entre os Tikuna, desde os que seguem estritamente as prescrições tradicionais, aos $\mathrm{Ti}$ kuna do Médio Solimões, entre os quais a maioria não fala mais a língua desse povo. Apesar dessa evidência de apagamento da memória, nessa área, o imaginário Tikuna é ativo, registrando-se referências a relações subaquáticas, por meio de lagos 'centrais', 'encantados', entre os Tikuna do Alto e do Médio Solimões.

Agentes que trabalham com povos indígenas estimam que mais de 53.544 (Siasi/Sesai 2014) Tikuna vivem no Brasil (FUNASA 2009), 8.000 na Colômbia (Goulard 2009) e 6.982 no Peru (INEL 2007) ${ }^{6}$, constituindo, assim, a população indígena mais numerosa da Amazônia. Além de falar a sua própria língua, também falam português e espanhol, cruzando frequentemente as fronteiras dos três países. As situações fronteiriças implicam a formação dos processos identitários. Não dispõem, no entanto, de território contínuo, sendo as terras Tikuna 'ilhas' confinantes com terrenos ocupados por pescadores, agricultores, comerciantes e indivíduos de outras categorias sociais.

A indianidade é reconhecida em códigos jurídicos de legislações que contemplam a especificidade indígena. A etnicidade constitui-se no campo das ideologias étnicas com base em processos identitários formados em relações contrastivas entre indivíduos pertencentes a povos que manifestam interesses divergentes em situações conflituosas. Desse modo, a antropologia do conhecimento Tikuna depende do entendimento das práticas que perpassam sua cultura em diferentes situações nacionais.

A cultura consiste num processo validado por práticas de transmissão do conhecimento dos anciãos de geração em geração. Entre as narrativas de criação do povo Tikuna destacam-se as 'histórias' sobre os gêmeos Yoi'i e Ipi, heróis culturais que pescaram os primeiros ho- 
mens no igarapé Eware que nasce na montanha homônima. Em sua narrativa sobre a procedência dos Tikuna, a artesã Wẽtanüna lembrou que Ipi, o irmão travesso, virou o mundo de cabeça para baixo, colocando o território Tikuna onde hoje é a Colômbia. O seu irmão Yoi ' i inverteu a situação conforme hoje está. Após esse feito, realizou viagem descendo o rio Amazonas e estabelecendo-se no Brasil.

Quando os Tikuna comentam os motivos figurativos dos artefatos rituais depositados em museus, usam muitos termos relacionados com a fronteira. Segundo afirmam, Ü'eane significa "divisão das terras de outros" ou "divisa de uma fronteira para outra". "Pode ser entre dois povos" ou "pode ser uma área de alguém dentro de um povo" quando se estabelece "divisão, para fazer cercado". Existe um termo específico para cerca: Puye'ü?

Os relatos dos índios sobre esses artefatos remetem à 'festa da moça nova', evocando histórias contadas na sua iniciação por meio de ritual de puberdade. Quando entram em cena as máscaras produzidas pelos próprios Tikuna, estas evocam o imaginário da relação com as forças da natureza, seres extraordinários ou antepassados Tikuna. As máscaras são associadas com os lugares de proveniência dos Tikuna: os lugares habitáveis, como as colinas ('morros') e as áreas próximas da floresta, e os confins inacessíveis da floresta e das áreas mais elevadas ('montanhas'), consideradas território dos entes encantados e das forças desconhecidas.

Entendem-se tais depoimentos como expressão manifesta que envolve entendimento intersubjetivo e que abrange a compreensão de cada Tikuna como membro do povo indígena em questão. As sequências rituais são atos de comunicação fulcrais para a análise de tais relações, concebidas em termos de 'estruturas sentidas', traduzindo o célebre termo structures of feeling cunhado por Raymond Williams (1977) para caracterizar a experiência vivenciada em atividades sociais em dado tempo e local e que repercute determinada cultura tal como percebida e partilhada por pessoas, indivíduos ou grupos sociais.

Nos seus depoimentos, ao contemplar os artefatos Tikuna empregados no ritual de puberdade feminina, evocam as guerras primor- 
diais, simbolizadas nas relações de oposição entre metades, facções, etnias ou correligionários de organizações rivais. Entre outras armas, a roda Türita consiste em uma armadilha para aprisionar e destroçar os inimigos. Essa roda aparece em representações míticas da passagem do 'mundo dos vivos' para o 'mundo de cima'. Apenas alguns conseguem atravessar a barreira, sendo que a maioria sucumbe no giro da roda Türita. Essa simbologia de fronteira perpassa as narrativas nas quais são apresentadas noções de sua relação com a natureza e com outras etnias. Esse imaginário é expresso através de enunciados que compõem a visão Tikuna da 'cultura de fronteira'.

As imagens de fronteira atravessam o próprio ritual de puberdade feminina, a chamada 'festa da moça nova', rito de passagem que envolve a transposição de limiares pela moça e por seu grupo de referência. Suas significações abrangem as temáticas da fertilidade da mulher e da natureza, da complementaridade das metades, da passagem do tempo, das obrigações sociais da mulher e da ordenação dos papéis e lugares na organização social Tikuna. A constituição da visão de mundo desse povo é alterada pela repercussão das transformações ambientais em seu dia a dia e em seu calendário de atividades sociais.

\section{Antropologia das relações céu-terra, clima e cosmovisão}

O presente texto se insere na trilha da vertente antropológica que dialoga com a astronomia cultural inaugurada por Hugh-Jones $(1979 ; 1982)$. Dialogamos ainda com a antropologia histórica da iconografia de povos pré-colombianos (Broda 2001, 2004) que examina etnohistoricamente como a medição do tempo era um instrumento de planejamento das atividades produtivas em termos rituais. A enunciação dos mitos e cantos no discurso ritual prescreve uma ordem socialmente definida que é justificada por instrumentos de consagração das hierarquias rituais (Broda 1982). Acidentes topográficos tais como montanhas têm destacado papel como lugares de ritualização e mediação das interpretações das rela- 
ções celestiais e terrestres. Além de indissociável do que ocorre na terra, o próprio céu é um campo de forças percebidas pelos humanos que reivindicam interferência sobre elas (Broda, Iwaniszewski \& Montero 2001).

Tal abordagem foi aprofundada na 'antropologia do clima', que considera a significação de relações céu-terra em processos meteorológicos (em Katz, Lammel \& Goloubinoff 2002; bem como Lammel, Goloubinoff \& Katz 2008; e Goloubinoff, Katz \& Lammel 1997). Esses compêndios compilam amplo espectro de trabalhos que consideram as percepções das transformações meteorológicas por determinados povos em determinadas condições sociais e geográficas, levando em conta o estabelecimento de estratégias de subsistência em face de tais fenômenos climáticos e a análise dos ritos e mitos relacionados à maneira como diferentes culturas percebem as variações do clima.

Reiteram-se aqui as críticas ao chamado 'reducionismo cultural's, impondo-se cautela na análise das causas dos eventos extremos quanto ao reducionismo climático e ambiental como uma nova versão do determinismo climático (Hulme 2011). O clima aparece como a variável predominante, mesmo quando outros fatores forem igualmente determinantes, que parece minimizar qualquer agencialidade ou meios de arbítrio dos sujeitos. Ben Orlov (1980), em uma abordagem alternativa aos pressupostos deterministas e reducionistas, enceta uma abordagem biunívoca das relações do homem com o meio ambiente, indicando a fertilidade das abordagens processuais baseadas em modelos de análise das estratégias de atores sociais (Ingold 1986; Wilbert 1996).

Exames históricos e arqueológicos acurados sobre como povos específicos observavam a natureza demonstram a orientação das atividades sociais no meio ambiente e a vinculação do calendário, considerando paisagem cultural e lugares significativos para as performances sociais (Faulhaber 1999, 2007), em termos de territorialidade. Em tais pesquisas a observação sistemática é perquirida como garantia de validação do conhecimento. $\mathrm{O}$ conceito de cosmovisão supõe o re- 
conhecimento de coerência na articulação de noções sobre o meio ambiente e o cosmos, em termos de experiências vividas em situações etnográficas específicas.

Considera-se aqui a esfera pública em sua heterogeneidade cultural, procurando reconhecer a contribuição de artesãos indígenas sobre os artefatos por eles produzidos como um aporte para um entendimento que considere tanto os sistemas concebidos em escala mundial, como mundos vividos localmente? .

\section{Pictografia e rodas rituais ${ }^{10}$}

Entende-se ressonância em termos das possibilidades de perceber a cultura que ecoa nos objetos como uma totalidade que é interpretada subjetivamente pelos indígenas (Gonçalvez 2005). A contemplação dos artefatos suscita interpretações sobre o objeto que o relacionam à sua cultura com base na qual eles foram produzidos. A reelaboração dos significados culturais vai além da visualidade, pois implica uma posição de escuta das muitas vozes (Greenblat 1991). Estou aqui alargando essa abordagem para considerar o impacto da cultura Tikuna nos artefatos rituais por eles elaborados. A escrita etnográfica deve estar atenta tanto ao assombro quanto à polifonia despertada por essa reverberação, sem deixar de ter em mente as descontinuidades entre o momento da produção dos artefatos e sua posterior reinterpretação.

A pictografia como expressão do pensamento indígena é definida por Carlo Severi (2015) em termos de 'mnemotécnica figurativa'. Entende-se a pictografia como codificação iconográfica da informação que realiza uma função na transmissão de conhecimento de geração a geração, através de, conforme se trata no presente trabalho, ritos de memorização de cantos e narrativas rituais. Incorpora-se aqui a definição de 'espaço quimérico' (Severi 2013) aplicada na análise das iconografias indígenas como sistemas gráficos dinâmicos ${ }^{11}$. Levando adiante essa abordagem, pode-se dizer que a leitura 'por indícios' exa- 
mina imagens correlacionadas às práticas sociais, envolvendo tanto processo memorização como a consolidação de formas de saber. Pode ganhar novos sentidos cada vez que se remete à lógica de relações expressas pela imagem. Na trilha de Severi (2013) o pensamento indígena visualiza quimeras gerando imagens operadoras de praticas sociais, produzindo assim dinâmicas de olhares e ações.

Trabalha-se aqui com o termo 'roda ritual', expresso pelos especialistas Tikuna presentes em oficina realizada em dezembro de 2002, referindo-se aos 'panos de tururi' classificados na categoria indumentárias de dança ritual, que também inclui objetos designados como máscaras e vestimentas. Em termos do uso ritual, as rodas são entendidas como 'escudos' (Gruber 1992) levados por mascarados no ritual de puberdade, uma vez que são utilizados para a proteção das entidades que os carregam. A presença dos mascarados na festa ilustra assim os perigos que ameaçam a moça durante seu período de reclusão, momento de liminaridade no qual esta se encontra sujeita a experiências extraordinárias de contato com imortais e no qual ela está rondada por seres invisíveis. Esses seres personificados pelas máscaras têm o poder de entrar na terra, no domínio dos encantados, desaparecer do convívio dos humanos e reaparecer em outros mundos, inacessíveis aos humanos. Em comunicação com os imortais, guardam os ensinamentos do povo Magüta, "preservando-os em um mundo distante das influências de outras etnias” (Faulhaber 2007:102). Afirmam que se não realizam a festa estão desprotegidos. Daí se depreende que o emprego dos 'escudos' denota entre os objetivos de realização do ritual a busca de proteção.

\section{Interpretando o universo Tikuna}

Hugo Camacho (2003) escreveu sobre uma possível interpretação analítica do Universo Tikuna. Segundo o autor, tal universo tem a forma de um globo e é dividido em três polos. Abaixo do mar Primigênio está o polo inferior, um lugar frio que regula os fluxos de água e tem- 
peratura. O polo superior corresponde a uma zona de fogo inatingivel ao pensamento humano.

O plano intermediário é dividido em camadas. Na inferior estão os pés (primeiro plano do eixo flexível), o mundo dos sem anus (o mundo da gente Ngeetüte). O joelho (segundo plano do eixo flexível) é o mundo dos sem olhos (o mundo da gente Ngerüta). A parte dos músculos (terceiro plano do eixo flexível) é o mundo dos anões (mundo da gente Metchita). No interior do quadril (quarto plano do eixo flexível), está o mundo em que vivem os mortais ('nós').

Abel Santos, linguista Tikuna que participou da oficina de 2002 para a interpretação de artefatos depositados no Museu Goeldi, concluiu seu mestrado no Instituto de Investigações Amazônicas da Universidade Nacional da Colômbia. Publicou um trabalho no qual analisou, a partir de depoimentos e desenhos dos anciãos, a divisão do universo Tikuna em camadas. Segundo reportam os próprios Tikuna, se a pessoa está de ponta cabeça, o observador vê a medula espinhal como o rio Amazonas. O rio é a medula, a desembocadura é o cérebro e a cabeça é o oceano Atlântico (Camacho 2003).

Diferentes depoimentos registrados em pesquisas de campo conduzidas no presente projeto indicam que os heróis culturais enviam ao submundo, às camadas inferiores acima descritas, aqueles que cometeram erros imperdoáveis, como os que cometeram incesto ou adultério, bem como as moças em processo iniciatório que saíram do recinto de reclusão para ver os instrumentos musicais proibidos. Os que cometem falhas menores, como as moças que se recusaram a se submeter ao ritual de puberdade, são enviados ao submundo onde vivem os anões, uma penalidade menos drástica do que o envio aos centros dos que não têm olhos ou não têm anus.

Os Tikuna descrevem ainda os planos superiores. No tórax (quinto plano do eixo flexível), está o mundo dos condores (a cuia celeste). $\mathrm{Na}$ cabeça (sexto plano do eixo flexível), conduz-se o manejo do pensamento, da sabedoria e do conhecimento (céu superior), logo abaixo do teto do Universo. A coluna vertebral e a medula espinhal - o Ca- 
minho da Anta - comunica-se com as outras partes do corpo, onde está o cerne da cultura Tikuna (Santos 2010).

De acordo com Camacho (2003), o pensamento dos pajés, dos anciãos e dos que estão sendo iniciados tem acesso aos mundos superiores viajando por um canal transparente que conduz a luz solar, conectando os diferentes mundos. Tal sistema supõe a integração do universo vivido pelos mortais que se comunicam através dos fluidos da energia vital (Goulard 1998; 2003). Essas energias se unem na cuia celeste com a Via Látea, com o 'Caminho da Anta' e com a base do mar primigênio (Camacho 2003).

No mundo em que vivem, os humanos situam-se sobre a terra e sob a atmosfera e, desse modo, podem vivenciar o circuito meteorológico. $\mathrm{O}$ pensamento dos anciãos, dos pajés ou da moça nova é capaz de se deslocar no cosmos através do canal transparente que conduz a luz solar, transpondo as diferentes camadas que compõem o universo. A transposição desse canal é um meio de atingir o conhecimento. $\mathrm{Na}$ cosmogonia estão presentes conceitos referentes à atmosfera e à astronomia, incluindo a explicação do nascimento do arco-íris que, nos relatos Tikuna, é uma variante da Cobra Grande ou Yewae', ser vivente que tem duas faces, uma correspondente à metade Ocidental e outra à Oriental.

Os Tikuna que participaram da oficina no Museu Goeldi em 2002 forneceram uma explicação da conexão entre fenômenos astronômicos e ambientais. $\mathrm{Na}$ base do universo, vive submersa a grande anaconda marinha (Yewae') ou Cobra Grande que permanece enroscada no eixo dos mundos. Yewae', para respirar, realiza periodicamente três tipos de movimentos: a) pequenos giros de rotação no sentido esquerda-direita, que são os que determinam a sucessão dos dias e das noites; b) um movimento ascendente que determina as fases crescentes da lua; e c) um movimento descendente que marca as fases decrescentes da lua. A conjunção desses três movimentos determina o ciclo de chuvas em cada um dos mundos, 'assim como as marés' (Camacho 2003:67). 
Restringe-se aqui o exame de aspectos da cosmovisão Tikuna no sentido de compreender como eles empregam-na na ordenação das atividades de subsistência. Na trilha de Herzfeld (2001) trabalha-se no âmbito da antropologia social, levando em conta o papel da escolha e da agencialidade em termos da razão prática. Entende-se que a cosmologia serve como fonte de argumentação da qual indivíduos e grupos extraem criatividade, explicações e justificativas de suas atividades, evitando-se, desse modo, equívocos decorrentes de ver a cosmologia como determinante da ação simbólica (Herzfeld 2001). A cosmologia, como um "corpo de concepções que enumera e classifica os fenômenos" (Tambiah 1995:130), varia conforme as normas e processos válidos em determinada forma de conhecimento como busca de orientação no mundo. Como os Tikuna se encontram em situação de contato, trata-se, antes de buscar princípios cosmológicos, de considerar a cosmovisão como embutida na invocação de performances. Nestas, ao teatralizar sentimentos e ideias associados à sua compreensão de relações vividas no mundo terreno, os Tikuna expõem seu calendário de atividades de subsistência, constituídas em situação de contato antigo com o mundo dos brancos.

O calendário dos Tikuna, conforme por eles descrito, é marcado pela época da vazante (nie'tchigü) ${ }^{12}$, que ocorre durante os meses de julho e agosto, quando a água para de subir e os peixes acompanham as águas em direção aos lagos. Nesses meses, é bom pescar peixes (tcho'ni aru ga), os animais voltam para os locais secos (na' ë'ü aru tchoügü), tratando-se de momento propício para a limpeza no roçado (taameë'tchicügü). Empregam o termo repiquete (nie'atchiü ou bainagüu), que acontece durante esses meses, para caracterizar uma nova subida das águas que estavam descendo, porém, a enchente não é tão grande quanto na época da alagação, tornando as águas a descer novamente. Durante o verão (taunecü), que ocorre de setembro a outubro, o rio atinge seu ponto mais baixo e o tempo é bom para caçar, fazer roça e plantar banana e macaxeira (variedade de mandioca). 
O fim da estiagem com o começo das chuvas é esperado a partir de setembro. A quantidade de água nos rios varia de acordo com o volume das chuvas, notadamente as que se registram nas cabeceiras dos rios e seus tributários. O impacto da chuva, contudo, afeta o dia a dia dos Tikuna com grande peso significativo, em termos do que poderá propiciar para as atividades de subsistência, mas também pela destruição que poderá causar se em excesso. Os Tikuna organizam as atividades em função das expectativas de menor ou maior cheia. A enchente dura cerca de quatro a cinco meses, voltando a baixar novamente no mês de junho. Durante a cheia (nibaitchigü), se observa a migração de peixes para fora dos lagos (tchoniarüigü), nascimentos de filhotes de araras (tchara'acü aru ya'e), chuvas rápidas (napuetcha), entre outros eventos. De março a maio, ocorre o período da alagação (macü), quando o rio Solimões atinge seu nível mais alto. Essa é a época de mais trabalho, denominado Dueegü nagu puracügü̈: desmanchar a roça (beegüü), descascar macaxeira (tü'e'ta gautchamüügüü) e mandioca, fazer farinha (ui naguta ügüü), tirar palha caranã para fazer casa (nagu titchuãcgü'ü) etc. Também é época de animais como veados (cowü) e cutias (tchigu) cruzarem o rio em busca de terras altas (naeügü aru we'ügü).

Na explicação sobre processos astronômicos e meteorológicos que alteram o ritmo da estiagem e das chuvas, os Tikuna conferem sentido à passagem do tempo e organizam atividades de subsistência. Agem de acordo com o calendário que é estabelecido com a observação dos movimentos lunares e solares, o que remete à "alternância entre o dia e a noite" analisada por Hugh-Jones (2015:673).

Voltamos assim aos temas das relações entre os dois irmãos, cuja união incestuosa gerou as estrelas Worecü ${ }^{13}$. O sol, em Tikuna Üaku, determina as atividades agrícolas e extrativas, e a lua é capaz de alterar a meteorologia, servindo como metáfora para a fertilidade da terra e da mulher e afetando indiretamente a temporalidade masculina. Descrevendo as fases da lua, em Tikuna Tawemacü, depoimentos comparam a metamorfose da menina transformando-se em moça após a 
menarca e, já como mulher, capaz de reprodução biológica e sujeita ao amadurecimento e ao envelhecimento.

\section{As rodas celestes produzidas em Puerto Nariño}

Com base nessas análises prévias, examinarei registros realizados, em setembro de 2012, na pesquisa de campo no município de Puerto Nariño, na Colômbia, interagindo com artesãos Tikuna do resguardo colombiano Ticoya, denominação que remete às etnias Cocama e Yagua. Esse resguardo foi criado em 1990, dispondo de aproximadamente 86.871 ha, expandidos posteriormente para pouco mais de 140.000 ha. Os indígenas, que se apropriam comunitariamente da terra, se congregam na associação denominada ATICOYA, através da qual reivindicam o reconhecimento da sua autonomia, o que juridicamente implicaria a figura jurídica de Entidade Territorial Autônoma, prevista na Constituição colombiana de 1991. O resguardo se sobrepõe ao município de Puerto Nariño, criado em 1984 pelo Departamento de Amazonas, na Colômbia. A história desse município é associada com a disputa territorial fronteiriça entre Peru e Colômbia pela região do trapézio amazônico, que remonta a 1922 e envolveu a garantia de direitos de navegação pelo Amazonas, finalizada com a aprovação do trato Lozano-Salomón em 1928. A formação dos povoados atuais deuse a partir da grande inundação de 1970, que criou uma situação de emergência e levou o governo a assentar as comunidades nas áreas de terra firme (Albarracín 2012).

Segundo informações da Fundação Natütama, a variação mínima da elevação das águas entre a seca e a cheia é de 8 metros, a média é de 10 metros. A mais alta variação, de 13 metros, ocorreu em 2011 quando se observou um recorde de seca. Já em 2012, observou-se um recorde de cheia. Tais eventos extremos causaram dificuldades para os pescadores Tikuna, uma vez que cheias despropositadas destroem suas roças e provocam a escassez de peixes, e a seca dificulta os deslocamentos. Além disso, como armazenam água de chuva, surpreen- 
dentemente, em dias de estiagem extrema, precisam comprar água potável, porque mesmo na Amazônia, a maior reserva de água doce do planeta, os mananciais de água limpa secam.

A escassez de água pode ocorrer na região quando passam mais do que 5 dias sem chover. Durante a estiagem, situações extremas ocorrem quando não chove durante mais de 8 ou 10 dias e as pessoas que vivem na área ficam privadas de água. A recorrência de tais eventos envolvendo situações calamitosas tem acarretado atitudes radicais, como o abandono das áreas remotas rumo à cidade, onde se dedicam a atividades do setor terciário, ainda que alguns prefiram manter-se nessas áreas embora sujeitos a situações de escassez e dependendo de recursos aleatórios provenientes do turismo. Afastando-se dos locais de caça, pesca e agricultura, estreitam os vínculos de inserção no circuito mercantil ao qual são subordinados mediante relações de servidão. Buscam a autonomia através da alternativa de serem reconhecidos como artesãos especializados capazes de oferecer uma produção cultural com atrativos étnicos.

Considera-se aqui o que falam mediadores entre o mundo Tikuna e os pesquisadores da Fundação Matütama no momento do registro etnográfico para a presente pesquisa. Antes de tratar da roda Mawü, examinaremos os significados atribuídos a dois desenhos celestes.

Esses desenhos foram feitos com hidrocor em 22 de setembro de 2012 pelo pescador Tikuna chamado Awe', conhecido por Casimiro Valério. Ele trabalha como pesquisador de animais aquáticos (botos, tartarugas) da Fundação Natütama e participa de treinamentos geográficos. Casimiro coloriu o primeiro desenho em azul escuro, com as estrelas (E'ta) em amarelo (Figura 1). Apresentou o segundo com a mesma disposição das estrelas em amarelo, só que com o fundo branco (Figura 2). Seus desenhos configuram uma visão dos asterismos celestes de modo um tanto quanto realista, ainda que tenha invertido a posição das constelações de Baweta (que fica na área do céu da constelação que conhecemos como Plêiades), Coyatchicüra (na área do céu de Touro) e de Wucücha (na área do céu da constelação de Órion). 
Destaca a estrela Woramacüri, ou Pacü, estrela de seis pontas que, segundo relatou, é a estrela da moça nova. $\mathrm{O}$ movimento dessa estrela, segundo a sua explanação, assume significado especial para os Tikuna quando se aproxima da Lua ou da Queixada de Jacaré, ou Coyatchicüra, porque esses momentos são propícios para a realização do ritual de puberdade. O desenho no qual usou predominantemente azul e negro (Figura 1) representa o percurso noturno subterrâneo do sol (Üakü). O no qual figurou as estrelas amarelas sobre o fundo branco (Figura 2) mostra o percurso diurno desse astro.

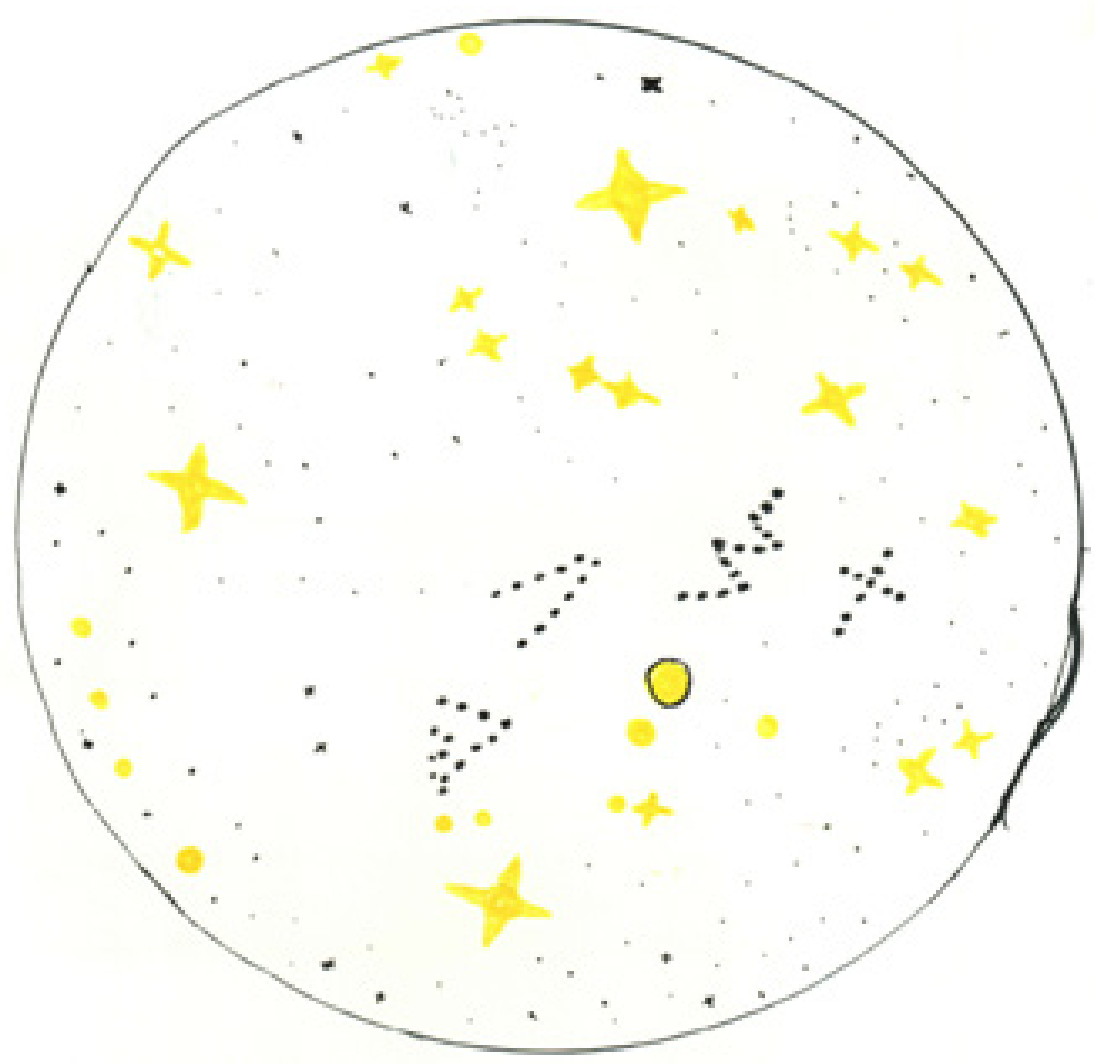

Figura 1. 


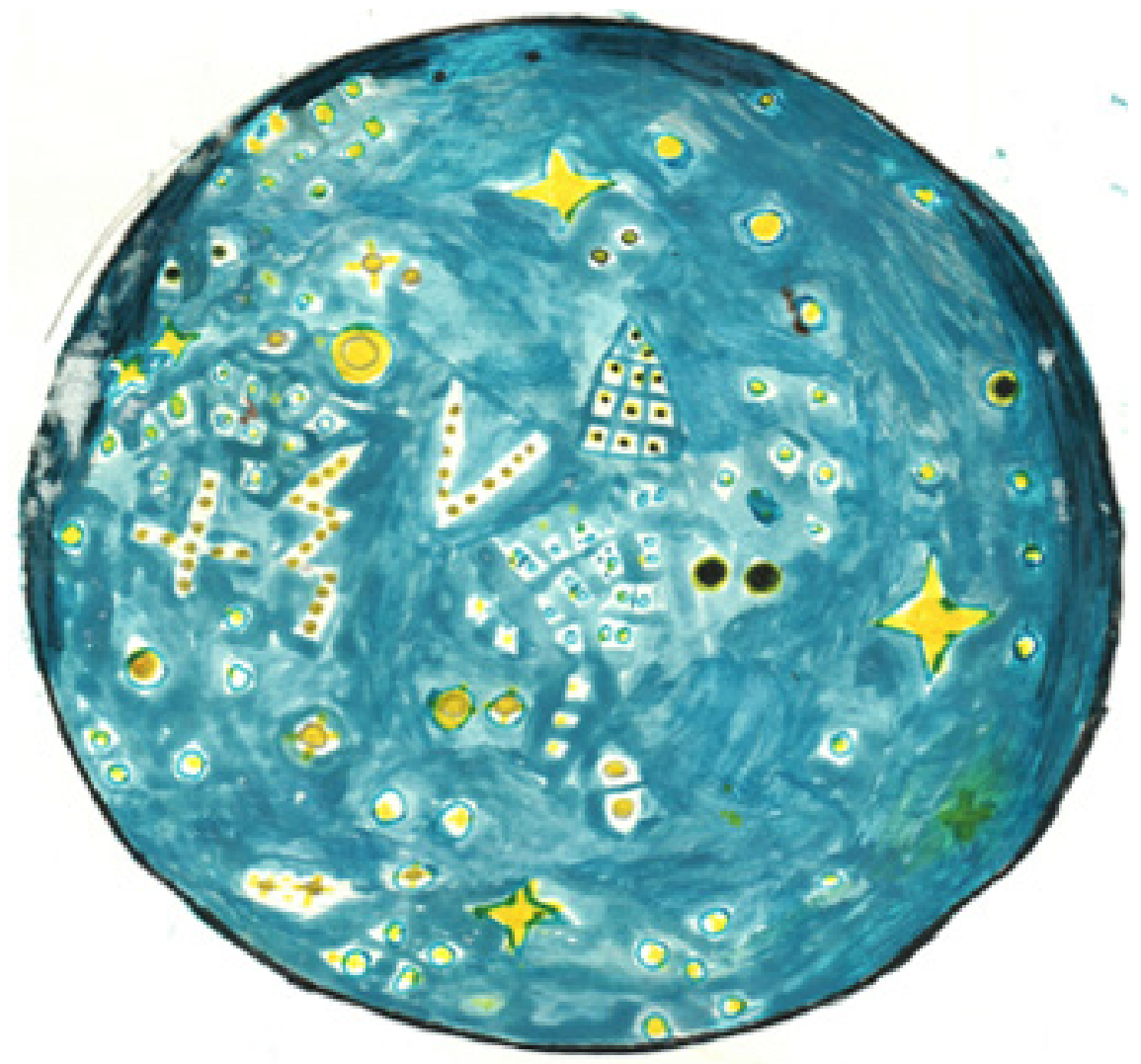

Figura 2.

A iconografia das rodas celestes destaca a visão Tikuna sobre as estrelas Worecü (Faulhaber 2004). Essas são relacionadas com o ritual de puberdade feminina. Trazendo alguns pontos levantados por S. Tambiah (1985:125), entendem-se os rituais em seu aspecto performativo. Para Tambiah, o ritual tem um 'aspecto dual'. De um lado ele sempre consiste na repetição de sequências que obedecem a determinadas prescrições estabelecidas na ordem do pensamento e sustentada em uma determinada ordenação cosmológica ou ideológica. De 
outro, todo antropólogo verifica durante as pesquisas de campo que nenhuma encenação de um rito, ainda que rigidamente prescrita, é exatamente a mesma, porque é afetada por processos peculiares ao modo de recitação oral do especialista e por certas características variáveis, tais como as características sociais e circunstâncias dos atores, os quais (excluindo-se eventos imprevisíveis e puramente contingentes) afetam assuntos como esferas de participação, interesse da audiência etc. Festas, ritos cósmicos e ritos de passagem, por mais que estejam prescritos, estão sempre ligados a reivindicações de status e interesses dos participantes e, portanto, estão sempre abertos a significados contextuais. Componentes variáveis tornam flexível o código referencial de cada ritual.

O sangue menstrual evoca aos Tikuna a primeira transgressão, quando a filha de Yoi'i atreveu-se a olhar os instrumentos proibidos, e os seres que os tocavam a esquartejaram. Isso tingiu o Eware da cor de sangue. Para proteger que as feras canibais sejam atraídas pelo cheiro da menstruação (Camacho 2003), após a menarca, a moça é submetida a período de reclusão, separada de seus familiares, em um quarto especial da casa paterna. Deve permanecer nessa situação para receber as instruções dos imortais, transmitidas também pelas anciãs. A purificação é almejada para assegurar o equilíbrio cósmico, a fertilidade da mulher e da terra. Inicia-se, logo após o início da clausura, o plantio de mandioca para produzir farinha para a alimentação e para a bebida que será oferecida aos convidados.

O sangue menstrual é visto como um poderoso fluido corporal, relacionado, em geral, com os cabelos, ambos associados a excrementos e poluição ritual, o que explica a depilação (Faulhaber 2006). Explicações psicanalíticas e antropológicas articulam o cabelo à separação ritual, atribuindo-se ao cabelo conotações mágicas, associando-o frequentemente à sexualidade, à fertilidade das colheitas e ao poder dos feiticeiros (Leach 1997) ${ }^{14}$. Considera-se que a moça reclusa passa por um momento delicado, submetida a experiências extraordinárias e deve portanto ser protegida. 
Quando inicia a festa, colocam a moça em um compartimento de reclusão, construído com talas de buriti (palmeira associada à proteção, pelo dono dos peixes, e à abundância), à frente do curral, também de talas de buriti, no qual estão guardados os instrumentos rituais. Espera-se que a moça esteja em comunicação com os espíritos dos ancestrais e integrada com o pensamento Magüta, povo pescado no lugar mítico Eware pelo herói cultural Yoi'i. A moça ali deve permanecer durante toda a noite, com a postura ereta, segurando uma vara (Yomeru). Acreditam que fazendo isso terá vida longa e muitos filhos. Fechando a porta desse curral, que deve estar voltada para Oeste, são colocadas duas varas de buriti em forma de X, simbolizando o conflito entre opostos representado na oposição entre as metades exogâmicas. À esquerda e à direita do X são desenhados corpos celestes correspondentes aos pontos cardeais e animais correspondentes a clãs pertencentes às metades opostas. A divisão entre metades também regula a entrada dos convidados da festa, de acordo com o Leste e Oeste.

Os filhos da relação incestuosa entre Lua e Sol tornaram-se estrelas móveis que correspondem, grosso modo, aos astros que conhecemos como planetas na astronomia moderna. A promoção do ritual da moça nova (Worecü) - central para a cultura Tikuna - é planejada conforme a observação do movimento dessas entidades que são visualizadas quando se aproximam à Lua e à Queixada de Jacaré, localizada como já exposto neste trabalho na área do céu onde reconhecemos a constelação de Touro. Os Tikuna as chamam estrelas Worecü ou Pacü, relacionando o ritual de puberdade com a visibilidade dessas estrelas. Para eles, elas sempre estão no céu e aparecem de acordo com os eventos vividos pelos humanos. A menor ou maior visibilidade relaciona-se com processos meteorológicos de acordo com a maior ou menor umidade atmosférica, desaparecendo alguns astros quando estão cobertos pela nevoa ou pelas nuvens.

Entre as figuras associadas ao ritual de puberdade feminina e à prática feminina do trançado, destacam-se a borboleta Berü e o pássaro Tchivirü, que podem anunciar a chuva ou a estiagem. Outras fi- 
guras remetem a entidades como os donos do vento, das chuvas e da tempestade e a cobra grande-arco-iris ${ }^{15}$. Estes se incluem entre os chamados üüne ou imortais (Oliveira Filho 1988).

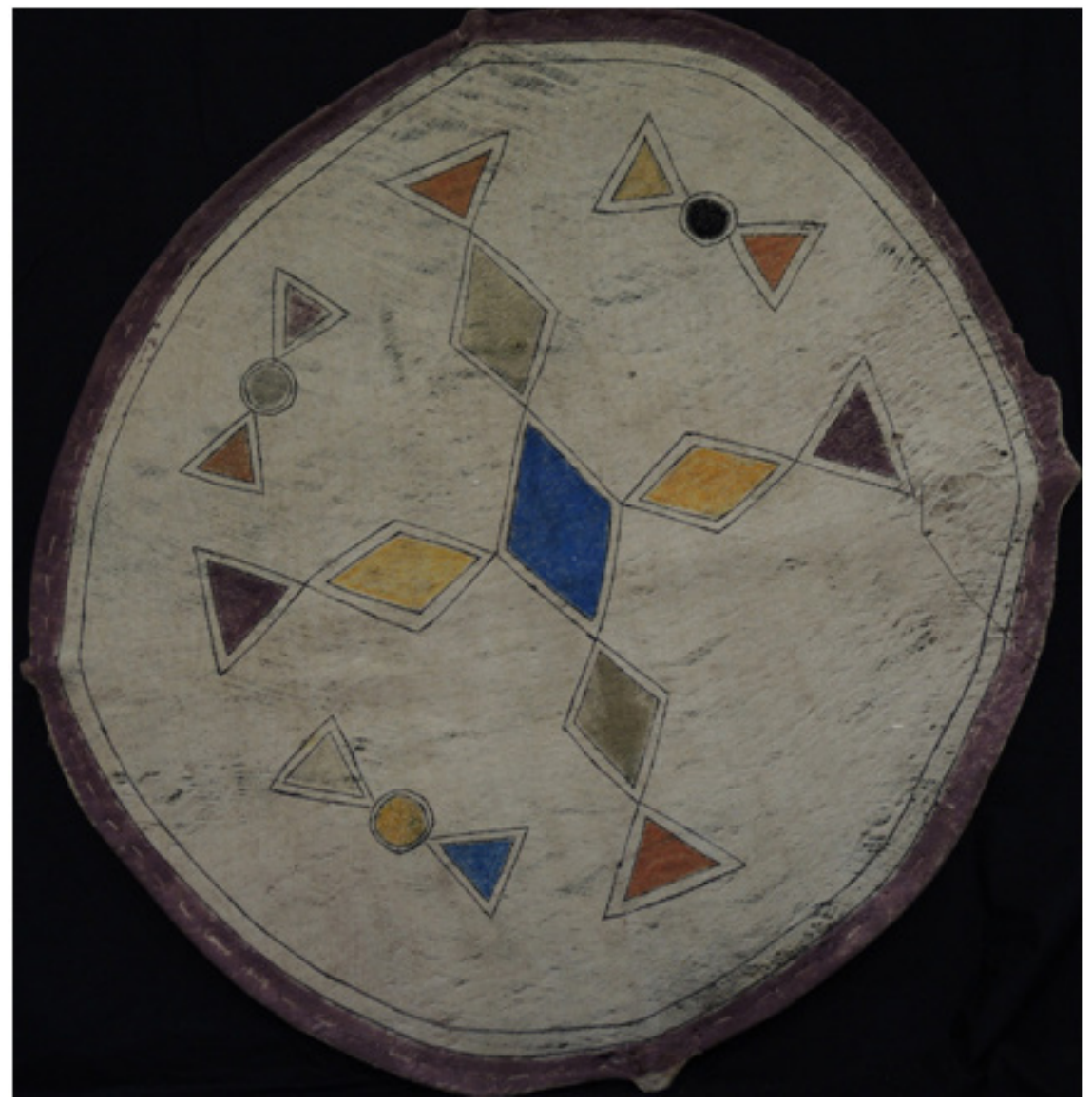

Figura 3.

A artesã Tikuna Wẽtanünana Tchoatüna fez a roda celeste, representada pela Figura 3, com entrecasca de árvores e pigmento vegetal 
natural $^{16}$, no dia 16 de agosto de 2012, na maloca Mawatcha. Sua denominação se refere ao nome de uma das irmãs dos heróis culturais Yoi 'i e Ipi e que saiu, junto com a outra irmã Aicüna, dos joelhos do patriarca Ngutapá. Wẽtanünana vive na maloca com o marido, três filhas com seus respectivos maridos e 10 netos. Ela é colaboradora eventual da Fundação Natütama, sendo convidada por sua capacidade como anciã, já que participou ao longo de sua vida de muitos rituais de puberdade Tikuna, e por sua capacidade de sistematização do conhecimento especializado por pessoas dessa etnia. Segundo descrição da artesã, no dia 23 de setembro de 2012, a roda representa o escudo de Mawü, o 'dono da chuva', cuja performance anuncia a chegada da intempérie. A artesã indicou no centro da roda o tronco Wone, ou Samaumeira Mãe (Ceiba pentandra (L.) Gaertn), transformando-se no grande rio. Interpretou o lago Tarapota como nascendo de uma importante reserva de água doce relacionada às cabeceiras do Amazonas. Indicou ainda o traçado do desenho dos sábalos que, após terem sido pescados por Yoi'i e Ipi, transformaram-se nos primeiros homens.

Em torno do tronco/coração do rio, constam três estrelas woramacüri estilizadas. Em sua fala, Wẽtanünana explicou que a ausência de um quarto corpo celeste, deixando um espaço vazio na roda ritual, correspondia ao lugar da lua nova ou da Queixada de Jacaré (Coyatchicüra), que antes de seu nascer helíaco desaparece do céu. Segundo seu relato, a figura expressa o começo do mundo, com a formação do rio Amazonas a partir do tronco de Wone ${ }^{17}$. Também corresponde à ausência de sol à noite, quando chove ou é oculto pelas nuvens ${ }^{18}$.

Detalhando sua explicação, Wẽtanünana relacionou a iconografia da roda à formação do grande rio. Sua explicação está associada a todo um conjunto de narrativas que "conferem sentido umas às outras" (Hugh-Jones 2015:662). A artesã relatou que, de acordo com a cosmogonia Tikuna, o mundo começou quando os seus antepassados - o povo Magüta - viviam na escuridão, porque a preguiça gigante segurava o céu, arrimada na árvore mítica Wone. O herói cultural Yoi’i 
lançou uma formiga de fogo nos olhos da preguiça, que soltou o céu, caindo este sobre a árvore Wone.

O peso do céu sobre a árvore liquefez o seu coração, formando as cabeceiras do rio Amazonas, das quais começaram a descer os sábalos (Semaprochilodus insignis) que Yoi'i e seu gêmeo mítico Ipi pescaram e transformaram-se nos primeiros homens do povo Magüta no igarapé Eware, referido como um tributário do igarapé Tonetü (São Gerônimo), que por sua vez desemboca no Solimões. Já no Brasil, Yoi'i ensinou esses primeiros homens a trabalhar, concedendo-lhe os nomes clânicos, associados em metades exogâmicas, a primeira reunindo aves e a outra, seres de casca, ou 'sem pena'. A relação entre tais metades está no centro da organização social desse povo. Os Tikuna de hoje dizem descender desses primeiros homens pescados no igarapé Eware e explicam seus problemas pelo afastamento do Eware e dos ensinamentos dos heróis culturais.

Foi ao atribuir tais significados à roda Mawü que a artesã tomou o objeto em seus braços e começou a cantar na língua Tikuna ao mesmo tempo que dançava desempenhando performance ritual de alta força alegórica. Wẽtanüna demonstrou perceber que a pesquisa estava articulada a indagações de ordem museológica. Habituada à interação, ainda que eventual, com a Fundação Matütama, que inclui entre suas atividades um museu realizado com a colaboração dos próprios Tikuna, a artesã colaborou com pesquisa que resultou no presente trabalho, permitindo a gravação de seu depoimento sobre a elaboração do artefato, fornecendo indicações para a interpretação de seus significados. Nesse sentido, entende-se que os objetos comportam forças culturais dinâmicas e complexas dos quais emerge e para as quais ele é configurado, na visão de mundo de quem o contempla. No contexto das sociedades nacionais e dos museus, a cultura indígena irá produzir uma reverberação dos contextos significativos em que foram produzidos.

Nesse caso, a ritualização implicava uma reivindicação de reconhecimento de seu conhecimento especializado da cultura - e da cosmovisão - Tikuna. Tal ato extrapolou a demanda econômica, uma 
vez que doou a roda como um índice material do conjunto de seus relatos, buscando legitimação do seu conhecimento da cosmovisão do povo ao qual se integra. Nesse sentido, tal ritualização pretende atravessar um limiar na medida em que visa cruzar barreiras temporais e espaciais, em uma viagem ao mundo da pesquisa e dos museus, na qual busca reconhecimento do seu status de especialista Tikuna. Sua interpretação da roda se dá enquanto artefato concebido para o ritual de puberdade feminina e decorado com a iconografia que expressa a cosmovisão Tikuna como um sistema de signos que envolve aspectos tangíveis das implicações do entendimento das relações céu-terra para a subsistência.

Todavia, ao enfatizar a ritualização da artesã ao explicar o artefato, considero a impossibilidade de tratar o evento ritual como uma atividade isolada, uma vez que se trata de uma dimensão constitutiva da cultura em jogo. Entende-se aqui que a artesã ritualizou a interação comigo ao expor sua interpretação sobre a roda ritual e figurou, como no artefato, a reverberação da cultura Tikuna. Tal figuração se estabelece de acordo com o seu entendimento do ritual que implicou a elaboração de tal objeto.

Apreende-se o desempenho de Wẽtanüna Tchoatüna como um 'ato de fala' em sua dimensão performativa, uma vez que atua no sentido de transmitir uma mensagem na interação com o processo de pesquisa conduzido em um trabalho antropológico. O tronco Wone, na a explicação da artesã, figura no centro do escudo de Mawü. Esse tronco é um núcleo central, o centro propulsor do qual se formam as nascentes do grande rio que é fonte de vida, mas também de destruição. A interpretação do significado desse núcleo tem uma dupla face, já que remete tanto à explicação da formação do rio dentro do ordenamento cósmico, quanto à afirmação de suas consequências para as práticas sociais que articulam a vida cotidiana em situações sociais específicas.

A artesã transmite sua mensagem no sentido de veicular o seu conhecimento em termos da cosmovisão Tikuna. Sendo assim, informa 
sobre sua cultura e conecta a sua visão do cosmos com o mundo social em que se situa. Recebi sua mensagem no momento do encontro etnográfico, consistindo o trabalho antropológico em reelaborar sua mensagem por processos de escrita que, embora leve em conta o encontro etnográfico como crucial, extrapola o seu lugar de circunscrição, abrangendo as referências antropológicas para o entendimento da dimensão ambiental da interpretação indígena.

\section{Concluindo}

Quando a artesã comenta a iconografia da roda ritual, ela está interpretando a cultura Tikuna, correlacionando os grafismos com os enunciados das histórias contadas de mãe para filha durante o ritual, no qual os nexos das relações céu-terra integram as suas explicações sobre a ordem do mundo. Quando toma a roda nos braços e começa a cantar e dançar, está ritualizando a significação cultural do artefato. Dialogando com a cultura Tikuna, faz ecoar as suas vozes, em uma demonstração polifônica do caráter multissituado do patrimônio cultural.

Tal ritualização é realizada no contexto de uma busca de reconhecimento do pensamento Tikuna. Busca também o reconhecimento de suas aptidões como artesã. Ao ritualizar o seu depoimento, Wẽtanüna reivindica o reconhecimento do modo como apreende a cultura Tikuna e da sua condição de produtora especializada em uma forma particular de produção cultural, que poderá propagandear a cultura Tikuna para audiências no mundo dos brancos, especificamente no campo da antropologia.

Wẽtanüna ritualizou a antecipação da chuva que pressentiu, segundo afirmou ao observar a névoa forte que dava um brilho especial às estrelas. Assim, fez poucas horas antes de começar a chover, um dia após o equinócio de setembro, quando o sol estava causticante e próximo ao zênite, ao fim da seca. A lógica de participação da artesã é paralela ao raciocínio causal apresentado pelas previsões meteorológicas 
em padrões científicos modernos que a artesã não desconhece, uma vez que são veiculadas pelos meios de comunicação. Incorpora conceitos 1 envolvendo relações causais tal como entendidos pelos métodos científicos modernos, visto que não são povos isolados, mas pessoas ou indivíduos em contextos multissituados de interatividade sócio-histórica. $\mathrm{O}$ pensamento mágico perpassa as interpretações dos artefatos Tikuna que mostram como esses indígenas percebem relações entre a astronomia, o meio ambiente e a meteorologia e interagem com os seres que determinam os processos que alteram sua vida.

Os astros celestes assumem conotações relevantes para as atividades cotidianas. Por exemplo, na alternância do sol e da lua, a significação da presença (luminosidade - brancura) ou da ausência (escuridão - pretura) do sol no dia ou na noite está associada ao sistema de significados abrangidos pelo cromatismo indígena que remete à importância da cor vermelha associada ao urucum, denotando o sangue menstrual, a fertilidade da terra e a própria dinâmica da vida e da morte e dos estágios intermediários como adolescência ou idade adulta. Assim como o aparecimento ou desaparecimento da Lua lembra a oscilação de branco e preto, luminosidade e obscuridade. Essa associação remete ao uso do jenipapo como corante negro no relato sobre a formação das manchas desse astro, que é significativo para o calendário feminino e para o ritual de puberdade após a chegada da menarca e que também marca as transformações da jovem em mulher e seu envelhecimento.

A elaboração indígena das imagens expressas na iconografia dos artefatos rituais, mediada pela cosmovisão, expressa determinada forma de ordenamento do mundo do ponto de vista dos nativos, baseando-se em princípios de experiência participativa, já que os Tikuna, hoje, apesar de manterem a própria cosmovisão que tem como referência seu universo cultural, também são indivíduos situados em uma ampla gama de interações em situações sociais e históricas.

Entende-se, em sua eficácia performativa, a ritualização de Wẽtanüna com a roda que confeccionou como um modo de lidar com os se- 
res que controlam as relações céu-terra e afetam a vida dos humanos. Trata-se, assim, de se apropriar de determinada forma de manejar as forças que ordenam o mundo. No terreno do imaginário, procura-se interferir sobre os eventos, de modo a procurar alcançar algum tipo de controle sobre os eventos significativos para ela e para o planejamento e a organização de estratégias de subsistência.

\section{Notas}

1 Agradeço às sugestões de Camile Melo, Márcio D’Olne Campos, Hannah Cavalcanti e Édwin Reesink.

2 Grafo aqui o termo Tikuna tal como convencionado pela Associação Brasileira de Antropologia. Embora em diversas publicações no Brasil se opte pela grafia utilizada pelos professores bilíngues desta etnia no Brasil, por exemplo, em Pinheiro, Soares, Carmo \& professores Tikunas (2014); no presente estudo analiso minha interação com índios Tikuna que atuam na Fundação Natütama, em Puerto Nariño, que utilizam a grafia com $\mathrm{K}$.

3 Grafa-se este nome conforme referencial fonológico de Marília Facó Soares (ip). O significado remete a "aquela que tem folha branca e (é) do grupo (pertence ao) grupo de [buriti] preto (preto = maduro). No caso de Wẽ, seu significado é "preto"”. 4 A artesã interpreta a roda ritual apresentada na Figura 3 em um momento diferente da festa de puberdade propriamente dita. Como a pesquisa foi realizada posteriormente a essa festa, não se trata aqui de reproduzi-la, nem analisá-la.

5 A pesquisa sobre a significação da iconografia dos artefatos rituais Tikuna começou em 1997 durante trabalho de campo do projeto sobre o Universo Tikuna coordenado por João Pacheco de Oliveira (Museu Nacional/UFRJ), quando realizei estudo sobre as narrativas Tikuna e o meio ambiente. Nessa primeira viagem aos Tikuna do alto Solimões em 1997, presenciei um ritual de puberdade feminina Tikuna que me despertou o interesse pelas máscaras rituais desse povo. Os próprios Tikuna expuseram que tinham interesse nos artefatos depositados no Museu Goeldi coletados por Nimuendajú, o que me levou a realizar levantamento das coleções de etnologia no Museu Goeldi e no Museu Nacional. A partir de então, visitei diferentes comunidades no Brasil e na Colômbia (Faulhaber 1999, 2002, 2003, 2004, 2006, 2009), quando levei fotos dos artefatos do Museu Goeldi, registrando os seus comentários ao contemplar os objetos. O projeto possibilitou uma oficina com especialistas Tikuna no Museu Goeldi que resultou no CD-Rom Magüta Arü Inü (Faulhaber 2003). Em 2011, a geógrafa Sarita Kendal, assessora da Fundação Matütama que participou da criação do Museu Matütama em Puerto Nariño, me convidou a visitar esse centro para compartilhar minha pesquisa com os Tikuna e conhecer o Museu Matütama. Programamos a atividade para setembro de 2012, quando realizei 
a etnografia para o presente trabalho. Informações sobre essa fundação podem ser encontradas em http://natutama.org.

6 Conforme citado em www.socioambiental.org/pt-br, acesso em 27/11/2016.

7 Os termos Tikuna registrados no presente parágrafo são grafados segundo critérios estabelecidos em Soares (2003).

8 Franz Boas e seus seguidores construíram uma visão alternativa às correntes do determinismo climático, as quais enfatizavam a superioridade do Norte temperado e do Ocidente, além da inferioridade do 'outro', e concebiam uma humanidade rigidamente hierarquizada, não só por influências ambientais, como também pela evolução racial. Boas (1911) e Lowie (1917) mostraram, através de observação sistemática e intensiva dos povos nativos da América, as complexas relações entre homem e meio ambiente. Diferentes exemplos de populações vivendo em meios semelhantes, mas apresentando diferentes padrões de comportamento, demonstraram que o meio não necessariamente explica a cultura e que compete ao indivíduo tomar suas próprias decisões. Como as séries de possibilidades abertas a cada um (a) dependem em parte do meio particular onde vive, a antropologia ressalta, a partir de Boas e seus seguidores, a interferência humana, enfatizando como o meio é imaginado pelos humanos (Boia 2005:94-95). Tal possibilidade parte da visão de uma autonomia relativa dos campos da cultura e da história natural, que, ao procurar evitar o determinismo climático, acabou isolando a cultura de outras áreas do conhecimento.

9 Considera-se aqui a contribuição de Urban (1993) para o entendimento da 'face pública da cultura', em uma sistematização que procura escapar às dicotomias entre racionalismo e tradicionalismo.

10 No escopo deste trabalho privilegiam-se os aspectos cognitivos da contemplação dos objetos rituais pelos índios. Indissociáveis, no entanto, da apreciação estética (Gell 1999). A magia como técnica não pode ser dissociada da eficácia simbólica enquanto forma de conhecimento do mundo. Graças a ela, o pensamento dos especialistas indígenas desloca-se no cosmos, atingindo mundos inacessíveis aos mortais (Chaumeil 2000).

11 Agradeço a Camille da Costa Melo, bolsista de iniciação científica que atua no projeto que resultou no presente trabalho, pelas leituras e discussões da bibliografia sobre iconografia e escrita pictográfica. $\bigcirc$ trabalho foi revisado por Ivna Feitosa. Sou grata igualmente a sugestões de Márcio D’Olne Campos.

12 Lima (2006) estabelece a etnografia das etapas do calendário dessa etnia, correlacionando com os termos citados tal como grafados pelos próprios professores $\mathrm{Ti}$ kuna que participaram da edição citada. No entanto, na abordagem aqui apresentada, empregamos observações registradas na própria pesquisa de campo, atendendo a depoimentos que enfatizam o início das atividades econômicas e não o calendário gregoriano que não tem correspondência direta com a determinação das práticas de subsistência aqui referidas.

13 Em depoimento registrado em 1997 (Faulhaber 2003), um ancião relatou a história do homem que perseguia a lua com sua canoa, tornando-se mais velho a cada mês e expondo, desse modo, como o ciclo lunar altera a passagem do tempo tanto para as mulheres quanto para os homens. 
Um exemplo da força dos cabelos para os Tikuna é que eles servem para separar os animais e descobrir aquele que fizera desaparecer o pai fundador: "Ngutapa, o pai de Yoi'i, havia sido comido por um bicho. Para descobrir qual bicho fora, Yoi pegou o cabelo da irmã dele para cercar todos os animais. Ele deixava passar aqueles que não tinham a carne do pai entre os dentes e assim descobriu e puniu a onça assassina”.

15 A cobra grande é um ser fronteiriço entre natureza e cultura, também configurada em versões referentes à figura do Honorato ou Cobra Norato, que se refere a uma entidade associada ao colonialismo e ao contato interétnico.

16 Segundo descrição da própria artesã, ela fez a roda com entrecasca de árvore coletada conforme tecnologia indígena, pintada com pigmentos vegetais naturais nas cores azul, amarelo, preto, marrom, laranja e bege. Empregou os seguintes materiais: Fibra naü (tucum/Astrocaryum vulgare), nhoe (tururi/líber de caxinguba/Ficus sp), madeira pune (pau-de-balsa/Ochroma spp), pigmento natural na cor marrom tchocanari (açafroa cor chocolate), pigmento o'ta (argila branca tabatinga), pigmento natural amarelo depaw (açafrão/Zingiberaceae), pigmento de naicü (semente preta), pigmento natural u'ta (urucum), pigmento natural vegetal azul (bure/semelhante à açafroa), pigmento natural cragiru, na cor violeta, pigmento natural archote cor alaranjado (bicha orellana), vareta de bambu. Ainda que não seja comum que as mulheres Tikuna façam esse tipo de artefato, pode ocorrer que anciãs respeitadas por terem participado de muitas festas participem dessa feitura, como presenciei em pesquisa de campo na comunidade Barro Vermelho (Bunecü).

17 Para a análise antropológica das narrativas Tikuna sobre a formação do Universo consultar Oliveira, 1988.

18 O sol é associado à cor vermelha brilhante e também ao urucu ou u'ta, que tem a função de irradiar fogo, alentar a aura solar, relacionada ao sangue que também é brilhante, quente e com cheiro forte (Valenzuela 2010).

\section{Referências}

ALBARRACÍN, Juan José Vieco, 2012. "El municipio de Puerto Nariño y el resguardo indígena Ticoya: historia local e historia oficial". In RUBIO, F. C., CHAUMEIL, J.-P. \& PINEDA CAMACHO, R. (eds): El aliento de la memoria: antropología e historia en la Amazonia Andina, pp 329-355. Bogotá: Universidad Nacional de Colombia.

BOAS, Franz. 1911. Mind and Primitive Man. New York: Macmillan.

BOIA, Lucian. 2005. The Weather and the Imagination. London: Reaktion Books.

BRODA, Johanna. 1982. "Astronomy, Cosmovisión, and Ideology in Pre-Hispanic Mesoamerica". Annals of the New York Academy of Sciences, 385:81-110.

. 2001. "Astronomía y paisaje ritual: el calendario de horizonte de ZacatepetlCuicuilco”. In BRODA, J., IWANISZEWSKI, S. \& MONTERO, A. (eds.): La montaña en el paisaje ritual (Estudios arqueológicos, etnohistóricos y etnográficos, 
pp. 173-199. México: ENAH-Instituto de Investigaciones Históricas/UNAMUniversidad Autónoma de Puebla.

BRODA, Johanna.2004. "La percepción de la latitud geográfica y el estudio del calendário mesoamericano”. Estudios de Cultura Náhuatl, 35:15-43.

BRODA, J., IWANIESZESKI, S. \& MONTERO, A. (eds). 2001. La Montaña en el paisaje ritual. México: ENAH-Instituto de Investigaciones Históricas/UNAMUniversidad Autónoma de Puebla.

CAMACHO, Hugo. 2003. “Cosmovisão Tikuna, um esboço”. In FAULHABER, Priscila (ed.): Magüta Arü Inü. Jogo de Memória. Pensamento Magüta, pp. 66-68. Belém: Museu Goeldi.

CHAUMEIL, J.P. 2000. Voir, savoir, pouvoir. Le chamanisme chez les Yagua de L'Amazone péruvienne. Genève: Georg Editeur.

FAULHABER, Priscila. 1999. “A Festa de To'oena. Performance, relato e etnografia Tikuna”. Amazônia em Cadernos, 5:105 - 120.

(ed.). 2003. Magüta Arü Inü. Jogo de Memória. Pensamento Magüta. Belém: Museu Goeldi.

2004. "'As estrelas eram terrenas': antropologia do clima, da iconografia e das constelações Tikuna. Revista de Antropologia, 47(2):379 -426.

. 2006."Iconography, Myths and symbolism inscribed in ritual artifacts: The Tikuna collection in a comparative perspective". Berlim, Baessler Archiv, 54:95-118.

. 2007. "O ritual e seus duplos: fronteira, ritual e papel das máscaras na festa da moça nova Tikuna”. Boletín de Antropología, 21:86-103.

2009. "Anthropology of Weather and indigenous cosmology inscribed in ritual artifacts”. In JANKOVIC, W. \& BARBOZA, C. (eds.): Weather, Local Knowledge and Everyday Life. Issues in Integrated Climate Studies, pp. 245-252. Rio de Janeiro: MAST.

GONÇALVES, José R. 2005. "Ressonância, materialidade e Subjetividade: as culturas como patrimônios”. Horizontes Antropológicos, 11(23):15-36.

GOULARD, J.P.1998. Les genres du corps. Conceptions de la personne chez les Tikuna de la Haute Amazonie. Thèse de Doctorat. Paris: EHESS.

2002. "Un objeto ritual: el chine o escudo de baile de los Tikuna". BAS. Bonn: Bonner Americanistsche Studien, 36:47-62.

2010. "Entre Mortales e Inmortales: El ser según los Tikuna de la Amazonía”. Mundo Amazonico, 1:359-361.

GOLOUBINOFF, M., KATZ, E. \& LAMMEL, A. M. (eds.). 1997. Antropología del clima en el mundo hispanoamericano. Quito: Abya-Yala.

GREENBLATT, Stephen. 1991. "Resonance and Wonder”. In KARP, I. \& LAVINE, S. (eds.): Exhibiting Cultures. The Poetics and Politics of Museum Display, pp. 42-56 Duhan/London: Duke University Press.

GRUBER, Jussara G. 1992. “A arte gráfica Tikuna”. In VIDAL, L. (ed.): Grafismo Indigena, pp. 249-264. São Paulo: EDUSP. 
HERZFELD, Michael. 2001. Anthropology: Theoretical Practice in Culture and Society. Paris: UNESCO.

HUGH-JONES, Stephen.1979. The Palm and the Pleyades. Initiation and cosmology in Nortwest Amazon. Cambridge: Cambridge University.

1982. "The Pleiades and Scorpius" In AVENI, A. \& URTON, G. (eds.): Ethnoastronomy and Archaeoastronomy in the American Tropics, pp. 183-201. New York: New York Academy of Science.

.2015. "A origem da noite e por que o sol é chamado de 'folha de Caraná". Sociologia $\mathcal{E}$ Antropologia, 05(3):659-697.

HULME, Ike. 2011. "Reducing the Future to Climate: A Story of Climate Determinism and Reductionism”. Osiris, 26(1):245-266.

INGOLD, Tim. 1986. The Appropriation of Nature. Essays on human ecology and social relations. Manchester: Manchester University Press.

KATZ, E., LAMMEL, A. M. \& GOLOUBINOFF, M. 2002. "Introduction. Eléments pour une anthropologie du clima". In KATZ, E., LAMMEL, A. M. \& GOLOUBINOFF, M. (eds.): Entre Ciel et Terre. Climat et sociétés, pp 15-21. Paris: IRD/Ibis Press.

LAMMEL, A. M., GOLOUBINOFF, M, \& KATZ, E. (eds.). 2008. Aires y Lluvias. Antropologia Del Clima en México. México: Publicaciones de La Casa Chata.

LIMA, Débora et al. 2006. O Calendário da Natureza. Ngiã nüna tadaugü $i$ torü nnãne Vamos cuidar de nossa terra. Belo Horizonte: UFMG.

LOWIE, Robert H. 1917. Culture and Ethnology. New York: McMurtrie.

MARCUS, George. 1998. Ethnography Through Thick $\mathcal{E}$ Thin. Princeton: Princeton University Press.

NAZAREA. Virginia. 2005. "A view from a point: Ethnoecology as Situated Knowledge”. In HAENN, N. \& WILK, R. (eds.): The Environment in Anthropology A reader in Ecology, Culture and Sustainable Living, pp. 34-39. New York: New York University Press.

NIMUENDAJÚ, Curt. 1952. "The Tukuna”. American Archaeolgy and Ethnology, XLV:1-167.

OLIVEIRA FILHO, João Pacheco. 1988. "O nosso governo": Os Tikuna e o regime tutelar. Brasília: MCT/ CNPq.

2015. Regime Tutelar e Faccionalismo. Politica e Religião em uma reserva Tikuna. Manaus: UEA.

PINHEIRO, P. I. \& SOARES, M. F. (eds.). 2014. Tchorü Dü̈güga'Tchanu. Minha luta pelo meu povo. Rio de Janeiro: UFF.

SEVERI, Carlo. 2013. "O espaço quimérico: percepção e projeção nos atos do olhar”. In: SEVERI, C. \& LAGROU, E. (eds): Quimeras em Diálogo: grafismo e figuração na arte indígena, pp. 25-66. Rio de Janeiro: 7Letras.

2015. The Chimera Principle: An anthropology of memory and imagination. Chicago: HAU Books.

SANTOS, Abel A. 2010. "Narración tikuna del origen del territorio y de los humanos”. Mundo Amazónico, 1:303-313. 
SOARES, Marília. 2003. "Acervo Etnológico e Inventário Lexical”. In FAULHABER, Priscila (ed.): Magüta Arü Inü. Jogo de Memória, pp. 57-59. Belém: Museu Goeldi.

URBAN, G. \& SHERZER, J. 1988. "The linguistic anthropology of native South America”. Annual Review of Anthropology, 17:283-307. . 1993. "Culture's Public Face". Public Culture, 5:213-238.

TAMBIAH, Stanley. 1885. "A performative aproach to ritual". In TAMBIAH, S. (ed.): Culture, Thought and Social Action, pp. 123-166. Cambridge: Harvard University Press.

1995. Magic, Science and the Scope of Rationality. Harvard: Cambridge University Press.

VALENZUELA, Hugo. 2010. El ritual Tikuna de la pelazón en la comunidad de AraraSur del Trapecio Amazónico - Una experiencia etnográfica. Tesis de Mágister. Letícia: Universidad Nacional de Colombia.

WILBERT, Johannes. 1996. Mindfull of Famine. Religious Climatology of the Warao Indians. Cambridge: Harvard University Press.

WILLIAMS, Raymond. 1977. Marxism and Literature. Oxford: Oxford University Press.

Abstract: This paper examines the impact of the cosmovision of the Tikuna on the iconography of ritual round wheels-like shields. The analysis of this impact includes symbolic actions that refer to the Tikuna thinking about the relations between earth and sky and about the effect of meteorological and environmental changes on their subsistence relationships. The main objects of analysis concern the meaning of the painted pictures on the artifact named The Master of the Rain (Mawü) as well as the dancing by the artist when she took that wheel in her hands, danced and chanted when explaining its significance The ethnographic analysis of the Tikuna female puberty ritual provides a necessary background for the anthropology and cultural astronomy in question.

Keywords: Tikuna; Cosmovision; Tikuna Indians; Sky-earth Relationships; Puberty Ritual; Cultural Astronomy.

Recebido em janeiro de 2017.

Aprovado em maio de 2017. 